\title{
COMENTARIO AL ARTÍCULO: EN CONTRA DEL POPULISMO REACCIONARIO: HACIA UNA NUEVA ARQUEOLOGÍA PÚBLICA DE ALFREDO GONZÁLEZ-RUIBAL, PABLO ALONSO GONZÁLEZ Y FELIPE CRIADO-BOADO*
}

\author{
Félix A. Acuto ${ }^{1,2}$
}

Las palabras son armas, y aquellas palabras que emanan desde los ámbitos académico-científicos siguen contando con un importante nivel de legitimidad en la sociedad civil, en las esferas estatales y de la política y en los medios de comunicación. Estas palabras pueden ser apropiadas desde los ámbitos del poder para sostener el status quo y reproducir diversas desigualdades y situaciones de dominación y opresión, o pueden ser tomadas por colectivos subalternos de distinto tipo a fin de adquirir visibilidad, denunciar situaciones de violencia de variado tenor, realizar demandas y reclamar y promover derechos. Si bien es algo que se ha dicho bastante, debemos seguir haciendo hincapié en la necesidad de ser sumamente críticos y reflexivos con respecto a las ideas y narrativas que producimos desde el mundo académico-científico. Especialmente cuando decidimos abandonar momentáneamente la comodidad que nos ofrece este mundo para intervenir en la realidad social, debemos realizar una seria reflexión crítica sobre nuestra praxis, evitando eludir el posicionamiento político, el cual debe ser claro, y evadiendo las ambigüedades, ya que éstas son terreno fértil para la manipulación y la tergiversación.

Las cosas por su nombre y sin ambiguiedades. Me pregunto entonces, ¿en quiénes están pensando los autores cuando hablan de populismo reaccionario? ¿En Donald Trump, en Michel Temer, en Evo Morales, en Rafael Correa, en Lula da Silva, en Cristina Fernández de Kirchner, en el nuevo presidente ultraderechista de Brasil, Jair Bolsonaro? En el contexto contemporáneo, no podemos hablar de populismo de manera liviana y sin una clara definición acerca de quiénes estamos hablando y junto a quiénes nos estamos posicionando. Debemos tener en cuenta quiénes son los que critican al populismo, que dicen sobre éste y dónde están posicionados. ¿Realmente queremos sumarnos a esas voces?
Deberíamos entonces ser precisos sobre lo que denominamos populismo, llamando a las cosas por su nombre. Políticos y administraciones como la de Trump, o lo que se viene en Brasil con Jair Bolsonaro, no es populismo, ¡son la derecha nacionalista, la oligarquía y los grupos asociados al poder! Y lo más paradójico, es que aquellos que ahora critican a los gobiernos populares latinoamericanos y a sus políticas sociales, representándolos como populismos corruptos y autoritarios, considerándose a sí mismos liberales republicanos (posicionamiento que reivindican los autores de este texto), son también la derecha y los grupos de poder.

En América Latina el populismo ha representado una contestación a estas oligarquías y grupos de poder, ha promovido los derechos de los subordinados (especialmente las clases trabajadoras) y se ha encargado de redistribuir los recursos del Estado en pos de la justicia social y no del capital financiero y especulativo. Es verdad que también se fue constituyendo en una entidad de muchas cabezas, entre las que se incluyen la corrupción, el paternalismo, el clientelismo político y cierto grado de autoritarismo (o de lógica "o están con nosotros o son nuestros enemigos"). Pero la agenda populista nunca ha dejado de tener en la mira al poder representado por las oligarquías terratenientes, los militares, los empresarios, la derecha o los sectores ortodoxos de la Iglesia Católica, buscando promover la justicia social (lo ha hecho, quizá deficientemente en varias ocasiones, pero lo ha hecho). Hoy día el populismo está siendo atacado ferozmente, pero estos ataques no son inocentes. Viene desde las oligarquías, en articulación con medios de prensa hegemónicos, el capital financiero y la complicidad del Poder Judicial con el objeto de reestablecer la hegemonía de la derecha política y económica. Este ataque, montado a caballo de la crítica a la corrupción de los gobiernos populistas y su supuesto autoritarismo (como si los negociados

\footnotetext{
* Nota de la editora: Chungara Revista de Antropología Chilena presenta los comentarios críticos realizados por ocho arqueólogos latinoamericanos al estimulante y provocativo artículo recientemente publicado en inglés "Against reactionary populism: toward a new public archaeology" en la revista Antiquity 2018, 92 (362):507-515, de los autores Alfredo González-Ruibal, Pablo Alonso González y Felipe Criado-Boado, cuya versión en español se encuentra disponible en www.chungara.cl. Los destacados arqueólogos Manuel Gándara Vázquez (México), Wilhelm Londoño (Colombia), Pedro Paulo A. Funari y Andrés Alarcón-Jiménez (Brasil), Henry Tantaleán (Perú), Alejandro Haber (Argentina), Félix Acuto (Argentina), y Dante Angelo (Chile), contribuyen sustancialmente al debate, desde sus visiones críticas de cómo el patrimonio y la arqueología pública es entendida y practicada en nuestros países latinoamericanos.

${ }^{1}$ Instituto Multidisciplinario de Historia y Ciencias Humanas, Consejo Nacional de Investigaciones Científicas y Técnicas, Buenos Aires, Argentina. facuto@gmail.com

2 Departamento de Derecho y Cs. Politicas, Universidad Nacional de La Matanza, Buenos Aires, Argentina.
} 
multimillonarios que estos gobiernos de derecha realizan desde el Estado, eliminando restricciones al accionar del capital trasnacional o condonando deudas millonarias que empresas privadas tienen con el Estado, no fueran también hechos de corrupción, o si el férreo control de los medios de difusión no fuera un acto autoritario) representa una embestida directa a las conquistas sociales y al empoderamiento de colectivos otrora subyugados.

Insisto, llamemos a las cosas por su nombre sin ambigüedades: criticar al populismo, o llamar populismo reaccionario a algo que no se termina de identificar, como se hace en este artículo, es posicionarse al lado de esta oligarquía de derecha o al menos darle más argumentos, ahora desde el ámbito académico-científico, para que dicha oligarquía arremeta con todo lo que aborrece: los derechos, el pensamiento crítico, los movimientos sociales, las voces disidentes, etc. Estoy seguro que muchos de los lectores de este artículo no van a pensar en Trump cuando lean populismo reaccionario sino en Evo Morales, Lula o Cristina. Las críticas que este trabajo realiza a lo que denomina populismo reaccionario y populismo epistémico, no difieren mucho de la manera en que, por ejemplo, la hegemónica cadena Fox News describe a Evo Morales.

Si bien estoy de acuerdo con algunos de los planteos que se realizan en este artículo, creo que no es el momento, especialmente en América Latina, para criticar a aquellos que trabajan en pos de la diversidad y la promoción de las voces subalternas, y mucho menos reclamar que dentro de esas voces también hay gente "mala" con intereses corruptos. Estas críticas en pos de traer aires frescos al debate académico, por más bien intencionadas que sean, van a trascender el ámbito de la academia para ser tomadas por la derecha reaccionaria y sus aliados en los medios de comunicación, tal como ya está sucediendo, para poner en duda la legitimidad de las identidades, derechos y reclamos de los colectivos subalternos (véase https://www.youtube.com/ watch? $\mathrm{v}=$ Gepme00yZ1E).

Creo que la postura debe ser la contraria. En un contexto de emergencia de la intolerancia y el racismo, como investigadores científicos debemos más que nunca alinearnos con los colectivos subordinados, apoyando sus proyectos y luchas y contribuyendo a su visibilización y la promoción de sus voces. No estamos en un contexto para criticar lo "políticamente correcto", sino por el contrario, debemos continuar en esta línea y en esta lucha por la tolerancia, el respeto y los derechos. Debemos salir de nuestra arrogante endogamia académica, la cual nos lleva a interesarnos por lo que sucede en nuestro pequeño mundo y en nuestras carreras profesionales, para ponernos a disposición de los subordinados y de quienes ven como los avances logrados en términos de justicia social comienzan a ser seriamente amenazados.
En los últimos años, desde lo que los autores denominan arqueología social, ha habido un afán por pagar las culpas coloniales de la arqueología, lo que ha gestado una cruzada por la transformación de la disciplina, la reparación y la vinculación. Programas de arqueología pública, reclamos por multivocalidad y activaciones patrimoniales han sido productos de esta cruzada. En la arqueología suramericana contemporánea se presentan tres situaciones. Por una parte, están aquellos que pasan por alto las críticas a la disciplina y no les interesan estos temas, ni la multivocalidad, ni la praxis. Los congresos y publicaciones académicas son clara prueba de esto ya que muestran que un amplio porcentaje del trabajo sigue estando enfocado puramente en el estudio del registro y la evidencia arqueológica. Por otra parte, están aquellos que se han comprometido seriamente, desde un marcado posicionamiento académico-político, con la descolonización de la disciplina y con la praxis, promoviendo el vínculo con otros saberes y poniendo en cuestionamiento, a través del conocimiento histórico, las representaciones estigmatizantes contra indígenas, mujeres, gays, afro-descendientes y otros subalternos. Ha sido justamente esta arqueología social, desmerecida en este artículo, la que ha promovido el cuestionamiento de la ciencia y el conocimiento occidental los cuales, en el caso de Argentina, han constituido la base teórica para justificar el avance sobre los pueblos indígenas, o declarar su desaparición y, por lo tanto, justificar la apropiación de sus territorios declarados desiertos. Finalmente están los que realizan actividades de arqueología pública, debaten sobre el patrimonio y hablan sobre (y por) los subalternos con el objeto de sumarse a una moda teórica.

Concuerdo con los autores de este artículo que en este último caso, que parte más desde lo políticamente correcto que desde la reflexividad crítica y el posicionamiento político, se terminan desarrollando actividades de vinculación que siguen reproduciendo estereotipos, que van a los territorios para contarles a la gente cómo era su propio pasado, y que se preocupan más por concientizar sobre la preservación del patrimonio (presentando al registro arqueológico como recurso no renovable que hay que conservar y no intervenir) en lugar de fomentar la participación y propiciar el empoderamiento. Concuerdo también con los autores que, justamente por su falta de reflexividad y por su praxis poco informada y posicionada, estos arqueólogos y arqueólogas no han problematizado la vinculación y con quiénes articulan. Así, vemos muchos trabajos que hablan del pueblo, de colectivos o de comunidades locales con mucha ambigüedad y sin definir claramente con quiénes se estarían vinculando y por qué, y mucho menos se interesan por cuáles son las demandas y reclamos que estos colectivos realizan a la arqueología. Cuando se habla de comunidades locales (un término muy empleado en la arqueología pública de América del Sur), ¿a qué se hace referencia?, ¿a los habitantes 
de un municipio?, ¿a colectivos indígenas?, ¿a una clase social determinada? No es todo lo mismo. Cada colectivo tiene su propia identidad, historia, problemas, intereses y objetivos. Es una obviedad decir esto, pero increíblemente cuando se debate sobre el patrimonio del "pueblo" o de las "comunidades locales", o sobre llevar adelante programas de arqueología pública para ellos, se ve claramente que no se problematiza la vinculación.

En lo personal soy crítico de estas formas de arqueología pública, activaciones patrimoniales y multivocalidad (sin multivocalidad), pero aun así celebro el intento. Celebro que el punto de partida de estas formas de vinculación, en su gran mayoría, siga siendo contestar a las estructuras de poder, visibilizar e intentar empoderar a los subordinados y desposeídos y promover su voz y participación. Creo que estas iniciativas necesitan ser mejoradas, pero no tratadas peyorativamente como vanos intentos políticamente correctos de populismo epistémico, porque todo lo que sea populismo, al menos en América Latina, está en la mira de la derecha conservadora disfrazada de liberalismo político y republicanismo. Al categorizar a estas iniciativas como populistas, lograremos deslegitimarlas y deslegitimar la lucha desde abajo. Debemos ser cuidadosos con las palabras que empleamos. Además, plantear que es importante el conocimiento subalterno para cambiar la arqueología, ¿es solo políticamente correcto? Reconocer los errores de la disciplina y buscar nuevos caminos de construcción de conocimiento que aporten a la descolonización, ¿es solo hacer lo políticamente correcto? Participar y promover y poner nuestro conocimiento a disposición para que el Estado promueva leyes que amparen a estos colectivos subalternos y que aporten a la igualdad y la justicia social, ¿es hacer populismo? Aceptar que, por ejemplo, los pueblos originarios son agentes sociales activos y sujetos de derecho, y no meros objetos de estudio, y aceptar que su patrimonio material no es simple registro arqueológico sino que está activamente conectado con su reproducción social y sus luchas políticas contemporáneas, ¿es ser reaccionario, racista o nacionalista?

Estoy de acuerdo con que debemos seguir trabajando para mejorar nuestra praxis como arqueólogos, pero en un sentido diferente al que propone este trabajo. En lugar de salir a difundir compulsivamente y sin evaluar las narrativas que transmitimos, a decirle a la gente quién es y cuál es su pasado, a hacer museos locales y a concientizar sobre la preservación del patrimonio, deberíamos ponernos a disposición de los proyectos y luchas de los subordinados. Ponernos a disposición implica poner a disposición nuestras capacidades, conocimientos y herramientas académicas a fin de dar cuenta de lo que los colectivos subordinados nos solicitan como expertos y no de lo que nosotros creemos que es bueno para ellos. Ponernos a disposición es escuchar lo que nos tienen que decir e informarnos sobre qué es lo que requieren de la arqueología, y cómo la arqueología puede ser puesta al servicio de la lucha contra el poder y la dominación, para dar respuesta a sus pedidos. Ponernos a disposición es salir de la praxis interna, del lenguaje académico críptico, de nuestras angustias y tribulaciones y de la crítica, a la crítica, a la crítica, para convertir a la arqueología y al discurso científico en una herramienta orientada a la lucha contra la desigualdad y la opresión. Ponernos a disposición implica escuchar, reflexionar y ponernos en acción.

Desde hace una década trabajo en articulación con una organización indígena de nivel nacional en Argentina, denominada Encuentro Nacional de Organizaciones Territoriales de Pueblos Originarios (ENOTPO). Dentro de esta organización macro, se encuentran distintas organizaciones territoriales de diferentes Pueblos Naciones Originarios que habitan en lo que hoy es Argentina (Diaguita, Huarpe, Q'om, Wichi, Guaraní, Atacama, Moqoit, Comechingón, Tonokoté, Mapuche, entre otros) y varias comunidades pertenecientes a estos distintos pueblos. El ENOTPO tiene como preceptos centrales tomar la voz en primera persona y que la política indígena esté en manos de los pueblos originarios para que nunca más otros hablen por ellos o los representen (ya sea la Iglesia, ONGs, la ciencia, etc.). El ENOTPO además rechaza todo tipo de personalismos, reivindicando la voz territorial. Si bien promueve la interculturalidad, la articulación con personas y organizaciones no indígenas son en términos de acompañamiento y aportes, evitando que terceros coopten las voces y las representaciones indígenas. Con mucha paciencia, distintos referentes y autoridades del ENOTPO me han enseñado sobre políticaindígena, interculturalidad y sobre el sentido de ponernos a disposición como científicos. A diferencia de la experiencia que parecen haber tenido los autores de este texto, donde el "pueblo" recibe pasivamente la enseñanza patrimonial ofrecida por los profesionales de la arqueología, quienes celebran todo lo venido desde abajo, yo he sido intencionalmente instruido y educado por esta organización indígena, la cual dista de ser un sujeto ideal construido por mis expectativas ético-políticas, sino que se trata de un activo sujeto político y de derecho. En mi caso, no ha sido una fútil celebración del pueblo lo que me ha motivado, sino un proceso de instrucción política.

En los últimos 30 años, y luego de años de represión, negación e invisibilización, los pueblos originarios en Argentina han ido ganando derechos, lo que ha llevado a un proceso de resurgimiento y visibilidad de las identidades, organizaciones, institucionalidad y prácticas culturales indígenas. Estas herramientas legales les han permitido salir del ocultamiento y poder realizar reclamos, especialmente sobre el territorio, sin miedo a ser reprimidos (aunque esto sigue sucediendo). La Ley 26.160 del año 2006 ha sido clave para los pueblos originarios y sus comunidades ya que ha suspendido 
las ejecuciones de sentencias y los actos procesales y administrativos orientados al desalojo de las comunidades indígenas hasta tanto se regularice la situación territorial de dichas comunidades. Esta ley puso efectivamente un alto a los desalojos de comunidades y comuneros indígenas y, simultáneamente, puso en marcha un proceso de reclamos por los territorios por parte de los pueblos originarios y sus comunidades.

La administración socialmente conservadora y económicamente neoliberal del presidente de Argentina, Mauricio Macri, quien en la Asamblea Anual del Foro Económico Mundial llevada a cabo en Davos en 2018 dijo que en América Latina todos descendemos de europeos, congeló toda política indigenista por parte del Estado y, como consecuencia de esto, el Estado nacional ya no se involucra en la mediación de situaciones conflictivas vividas por los pueblosindígenasen susterritorios. Sumado a esto, se ha iniciado un proceso represivo contra los colectivos indígenas, lo que ha producido muertes (como el asesinato de Rafael Nahuel en manos de las fuerzas del orden) y un intento de criminalización de la lucha indígena. Se ha declarado, por ejemplo, como terroristas a organizaciones Mapuches, sugiriéndose vínculos con las FARC de Colombia. Esto ha envalentonado a los capitales privados y a los terratenientes, quienes en asociación con la oligarquía política nacional y provincial, los medios de difusión y el poder judicial, han comenzado a atacar y buscar deslegitimar los reclamos indígenas y la misma identidad de quienes realizan estos reclamos, acosándolos de "falsos indios" oportunistas. Para evitar que los colectivos de pueblos originarios se amparen en el marco de derecho indígena nacional e internacional, estos grupos de poder comienzan a poner en duda la identidad indígena, la legalidad de las comunidades originarias (diciendo que son una muestra más de la corrupción del gobierno populista de los Kirchner ya que éstas fueron creadas por simples motivos de clientelismo políticos) y la legitimidad de los reclamos sobre territorios específicos (argumentando que en realidad esa gente que reclama no es de allí sino que vinieron de otros lados, incluido Chile como en el caso de los Mapuches). Así, demandas indígenas ajustadas a derecho pasan a ser representadas como tomas ilegales de tierras por parte de gente o comunidades que "inventaron" su identidad originaria producto de la influencia vil del populismo. Los indígenas empiezan a ser representados por el Estado y los medios hegemónicos de difusión aliados como "falsos indios" usurpadores, y los terratenientes como "pobres vecinos" que fueron afectados por las políticas del gobierno populista (véase:https://www.clarin.com/ opinion/fantasma-diaguitas-disputa-absurda-cruelvalles-calchaquies_0_r1UFd1Pal.html; https://tn.com. ar/politica/asi-es-la-guerra-por-la-tierra-en-tucumansalta-y-neuquen_816334; https://www.youtube.com/ watch?v=Gepme00yZ1E; https://www.eltribuno.com/ salta/nota/2018-9-22-0-0-0-diaguita-calchaqui-punto-de- inflexion-en-el-conflicto-por-la-tierra). Este, por ejemplo, ha sido el caso durante el juicio que recientemente (septiembre-octubre 2018) se desarrolló en la provincia de Tucumán contra los asesinos de la autoridad indígena de la Comunidad Los Chuschagastas, Javier Chocobar, en el año 2009 en manos del terrateniente Darío Amín y los ex policías Luis Gómez y José E. Valdivieso. En algún punto, lo que era un juicio por un asesinato se transformó en un juicio sobre la identidad indígena de Chocobar y la Comunidad Los Chuschagasta, y si el marco de derecho indígena debía ser tenido en cuenta o no durante el proceso. Argumentos tomados de publicaciones históricas y arqueológicas han sido, y son, esgrimidos por estos grupos de poder en esta cruzada por negar la identidad y la pre-existencia de los pueblos originarios en los territorios. Las palabras son armas.

Entonces, y ante este contexto reaccionario, no creo que el modelo liberal y multi-vocal de las ciencias sociales y las humanidades haya dejado de ser válido mientras implique pensamiento crítico y praxis y mientras siga promoviendo la participación. Tampoco creo que se trate de provocar al "pueblo", tal como propone este artículo, sino que el objeto debería ser la lucha contra los grupos de poder, la desigualdad y la opresión. La arqueología y lo que nosotros denominamos patrimonio importa. En el caso de los pueblos originarios, el patrimonio y el conocimiento arqueológico sirven para sostener los procesos de resurgimiento identitario y autorreconocimiento y para demostrar la pre-existencia indígena en los territorios. ¿Qué sería provocar en lugar de adular o contar cosas incómodas que problematicen y compliquen las narrativas, historias e identidades? ¿Escribir nuestros artículos usando el femenino es la provocación en la que están pensando los autores? ¿Poner en duda las identidades indígenas y sus derechos y reclamos sobre el territorio? ¿Decirles que entre ellos hay "indígenas malos" y poner en duda sus reclamos? ¿Es ir a educar a las oligarquías y grupos de poder, a quienes no les importa mucho lo que la arqueología tiene que decir, cuando lo que realmente piensan es que el Estado dilapida recursos financiando a la arqueología? No es una cuestión de generar, como dicen los autores, "una pedagogía crítica y transformativa que enseñe sobre la arqueología y utilice la arqueología para ofrecer un aprendizaje". En este contexto de resurgimiento de la derecha reaccionaria y de expansión del poder del mercado, debemos seguir posicionados en el llano (no creo ni que Childe ni Renfrew, quienes tuvieron un amplio alcance fuera de los círculos académicos hayan despertado conciencias o generado cambios en el orden del poder), es momento de escuchar, aprender y, a partir de ello, ver cómo podemos emplear a la arqueología y el conocimiento para sostener las luchas jurídicas de los subalternos. Es momento de identificar a los verdaderos enemigos, que son la derecha y el neoliberalismo, incluido el que está presente en el ámbito académico. 